\title{
Selectivity of Fusarium Culture Filtrates in Agar Media
}

\author{
R. Alconero and Alma G. Santiago ${ }^{1}$
}

INTRODUCTION

A number of agar media contain various antimicrobial agents for the isolation, enumeration and identification of Fusarium spp. from soil $(1,2,4,5) .{ }^{2}$ Papavizas $(3)$ recently evaluated several of these media under standardized laboratory conditions.

In 1961 Parmeter and Hood (4) reported a selective medium containing culture filtrates of Fusarium solani (Mart.) Appel \& Wr. f. sp. phaseoli (Burk.) Snyd. \& Hans. for its isolation from soil in dilution plates. They found that the medium restricted the numbers and growth of competing fungi, and simplified the identification of $F$. solani f. sp. phaseoli colonies. The potato-dextrose broth filtrate medium retained its inhibitory and selective properties when diluted to $\mathbf{5 0}$ and $\mathbf{7 0}$ percent. Autoclaving did not destroy the filtrate properties.

Media having selectivity for forms of Fusarium species would be very useful in studies of these forms and their responses to manipulation. We studied the selectivity of culture filtrates of $F$. oxysporum f. sp. vanillae, $F$. oxysporum and $F$. solani isolates on the linear growth in agar, spore germination, and growth in soil plates of these and other soil fungi.

\section{MATERIALS AND METHODS}

\section{DETERMTNATIONS OF LINEAR GROWTH IN AGAR}

We incubated two isolates of $F$. solani and two isolates of $F$. oxysporum, including $F$. oxysporum $\mathrm{f}$. sp. vanillae, at $28^{\circ} \mathrm{C}$. for 14 days in potato dextrose (PDB) and nutrient broth (NB). Isolates $(0.2 \mathrm{~cm}$. dia. discs of a 1-week old Czapeck agar culture) were placed in $500 \mathrm{ml}$. of broth in 1000 ml. flasks. At the end of the incubation period the broth cultures were filtered, and agar was added to the filtrates to make 2-percent agar media. The media were autoclaved for 15 minutes, poured into sterile petri plates, and left for 1 day to harden. Potato dextrose agar (PDA) and nutrient broth agar (NBA) were prepared without the filtrates as controls.

A 4-mm. diameter water agar culture of one isolate was placed on the surface of the agar media. Diameter of each isolate was recorded daily in

1 Research Plant Pathologist and Biological Laboratory Technician. Crops Research Division, Agricultural Research Service, U.S. Department of Agriculture, Federal Experiment Station, Mayagüez, P.R.

Italic numbers in parentheses refer to Literature Cited, p. 146. 
the different media until the cultures covered the agar surface. Each isolate was replicated three times in each filtrate and control media. The experiment was repeated twice.

\section{DETERMINATIONS OF SPORE GERMTNATION}

The isolates were incubated as previously described, except for use of 250 $\mathrm{ml}$. of broth in $500 \mathrm{ml}$. flasks. Half of each filtrate was autoclaved for 15 minutes and the other half was filtered through a Seitz filter. The same procedure was followed for the control broths. Ten milliliters of a filtrate were poured in a small 2-inch diameter petri plate; and a sterile film of cellophane (first washed with acetone and distilled water) was placed on the filtrate surface.

Macro- and microspores of $F$. solani (B) were obtained from a 2-weekold Czapeck agar culture incubated at $28^{\circ} \mathrm{C}$. To separate spores from the mycelium we used a spatula and sterile distilled water. The spores were washed three times by centrifugation and resuspended in water. About 10 spores were used per low-power field by diluting with sterile distilled water. After spreading the spore suspension $(2 \mathrm{ml}$.) on the surface of the cellophane film, spore germination was observed hourly during 5 hours. One final reading was made 8 hours after the first observation. There were three replicates per trial in each of the three filtrates of each medium. The experiment was repeated twice.

\section{DETERMINATION OF GROWTH IN SOIL PLATES}

Unsterilized and sterilized soil infested with $F$. oxysporum f. sp. vanillae and $F$. solani (B) were employed to determine the selectivity of the filtrates on fungi developing from soil or humus particles. The artificially infested soil was prepared by autoclaving $40 \mathrm{cc}$. of rich garden soil for 1 hour in slanting, 100-ml. glass bottles. One day later a 2-cm. diameter disk of a 4-day old Czapeck agar culture of one isolate was placed on the soil surface and incubated for 1 week at room temperature ( 25 to $28^{\circ} \mathrm{C}$.).

Soil samples $(100 \mathrm{mg}$.) taken from the bottles after mixing the contents thoroughly, were distributed in 10 petri plates. Garden soil, soil infested with $F$. oxysporum f. sp. vanillae, soil infested with $F$. solani $(\mathrm{B})$, and a mixture of the infested soils were represented in 10 petri plates for each filtrate and control medium.

Media consisted of potato-dextrose broth and nutrient broth (with and without a previous 2-week Fusarium culture). The broths were filtered and agar was added to make a 3-percent agar medium. The filtrates were autoclaved 15 minutes. Eighty milligrams of streptomycin sulfate and $60 \mathrm{mg}$. of rose bengal per $1,000 \mathrm{ml}$. were then added to the media. Approximately $15 \mathrm{ml}$. of medium were poured into each plate, and the soil particles were 
distributed through the medium with a gentle motion of the plate. Readings of the developing colonies were taken 48 hours after the plates were incubated at $28^{\circ} \mathrm{C}$. Twenty-five isolates were taken at random from each 10-plate group containing unsterilized garden soil. The experiment was repeated twice.

\section{Legend}
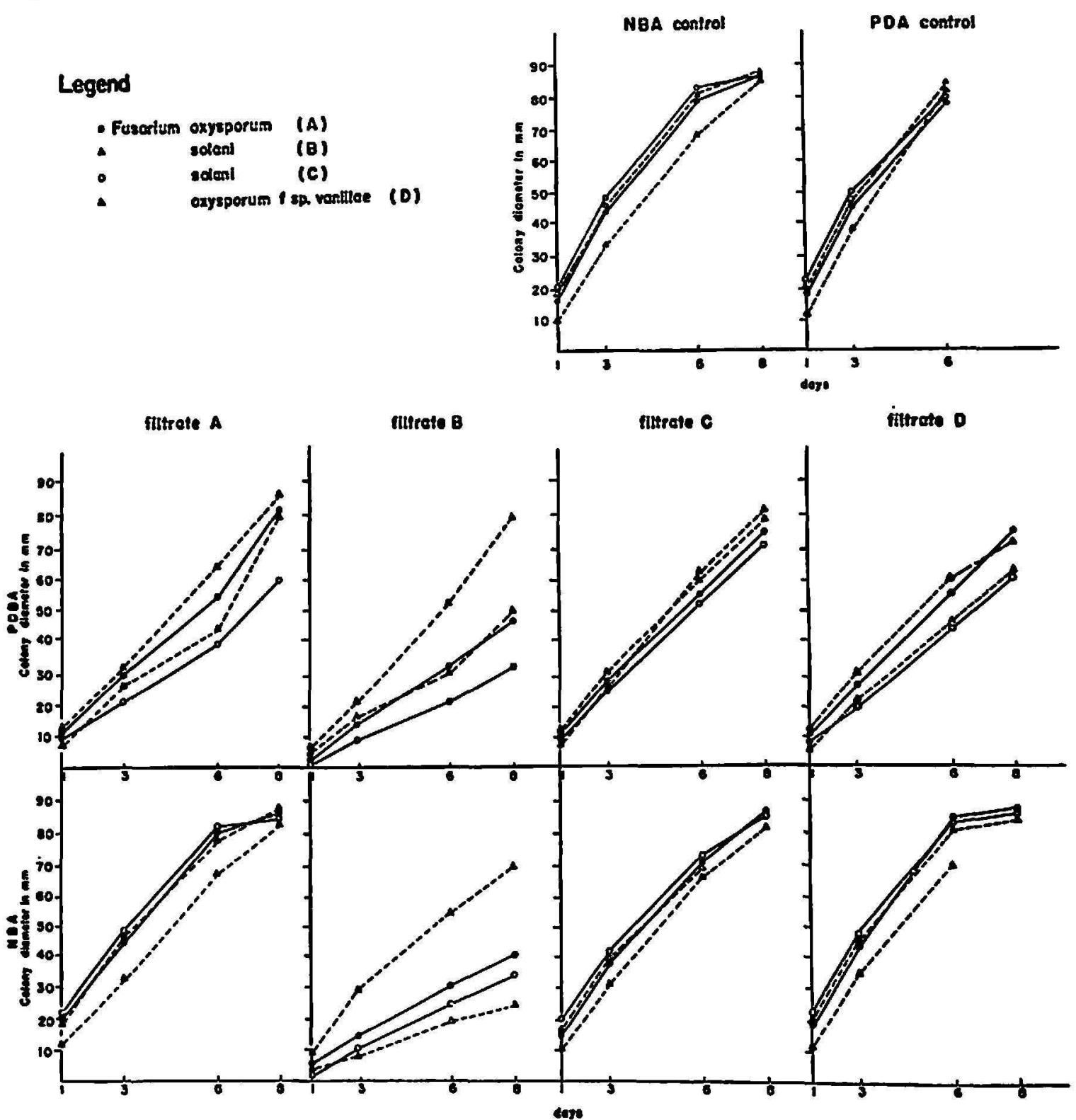

Fig. 1.-Linear growth in agar plus filtrates of $F$. oxysporum and $F$. solani isolates.

\section{RESULTS}

\section{IINRAR GROWTH IN AGAR}

Fusarium oxysporum in its own filtrate (A) media grew at approximately the same rate as in the controls. Inhibition was greatest in $F$. solani (C) in PDBA medium with filtrate A. Apparently other fungi were not inhibited (fig. 1). 
The greatest inhibition of linear growth in agar, as compared with the controls, occurred in PDBA and NBA with filtrate B. The inhibition was selective in both media. Fusarium solani (B) grew best in its own filtrate media, whereas the other fungi grew more slowly than expected from observations in the controls. There was no appreciable inhibition in media with filtrates of $F$. solani (C) or $F$. oxysporum f. sp. vanillae (D).

\section{SPORE GERMINATION}

The germination of $F$. solani (B) spores was more rapid in both media without filtrates, whether sterilized with heat or with a Seitz filter. Nutrient broth apparently was the better medium, with 45-percent germination by the fourth hour of incubation as compared with 25 percent in potato dextrose broth (fig. 2). Germination was much slower in filtrate media, regardless of
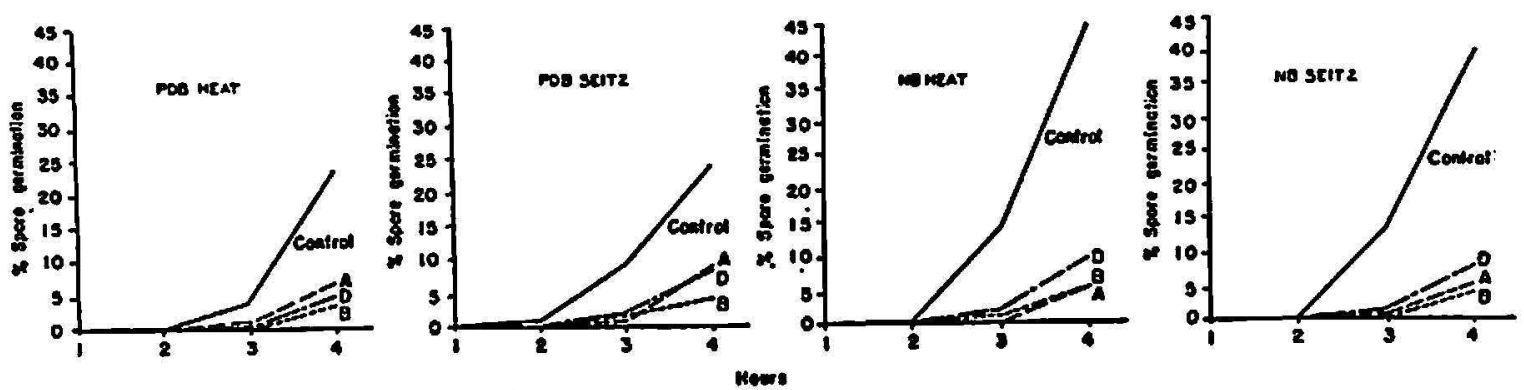

Frg. 2.-Spore germination rates of $F$. solani (B) over filtrates of $F$. oxysporum and $F$. solani isolates.

filtrate. Use of filtrate B from $F$. solani (B) did not accelerate germination of $F$. solani (B) nor did other filtrates inhibit germination rate.

\section{GROWTH IN SOIL PLATES}

Figure 3 illustrates the growth of fungi on filtrate media from $F$. solani and $F$. oxysporum f. sp. vanillae broth cultures and from control broths. Counts were lowest in soil plates with PDB filtrates, but much higher with the PDB control broth alone. The $F$. solani filtrate decreased the number of colonies appearing in all soil plates. The $F$. oxysporum $\mathrm{f}$. sp. vanillae filtrate in PDB decreased the number of colonies of itself less than in NB. Colonies were more numerous than in the $F$. solani filtrate in the same media but the differences were small. In soil containing both fungi the use of filtrates did not, apparently, favor either fungus; and colonies were indistinguishable.

PDB agar without filtrates allowed a greater number of colonies to develop in nonsterile soil. At random selection of colonies from the soil plates resulted in a wide variety of heavily sporulating species, but there was no apparent selection of fusaria when filtrates had been added to the media (table 1). 
E. soleal (A)

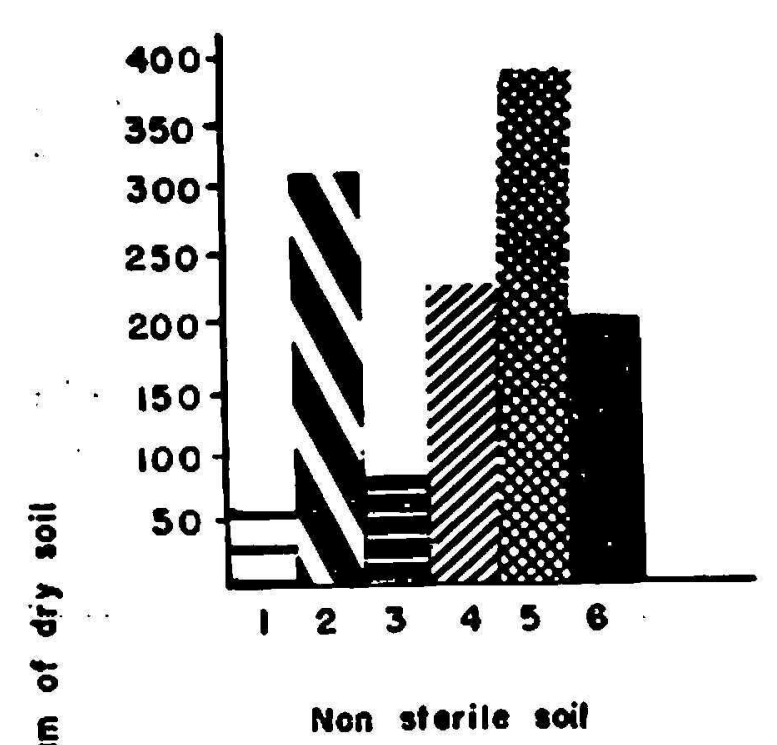

8

5

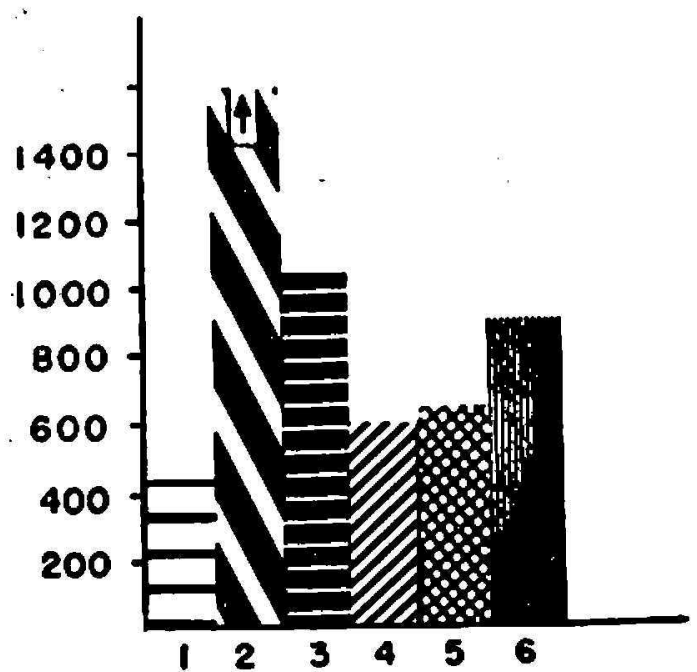

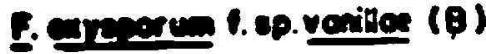

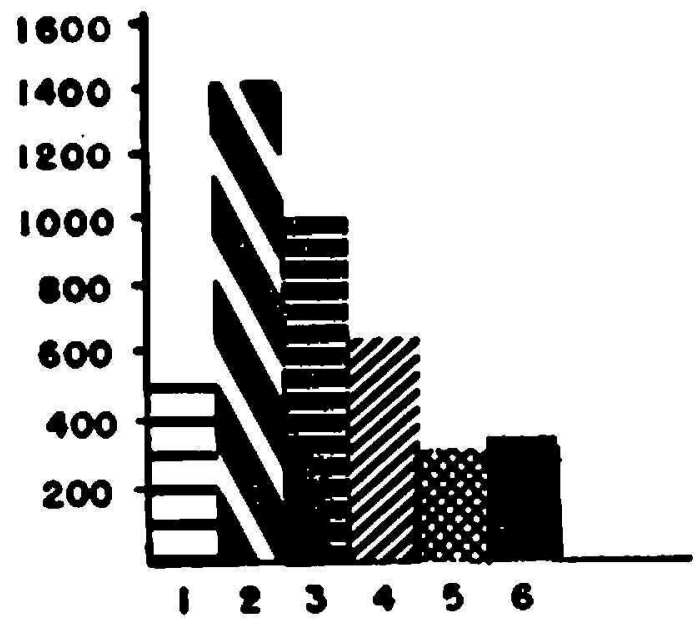

$A+B$ soll

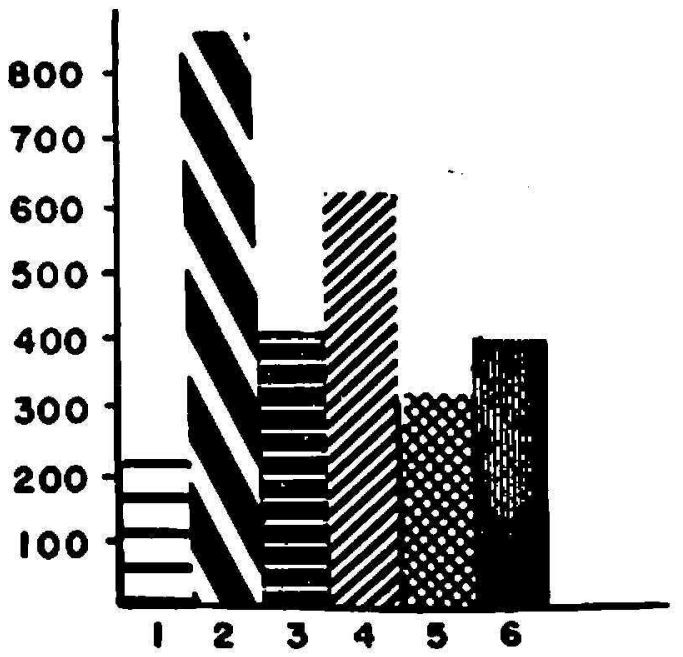

Fre. 3.-Fungal colonies in soil plates with filtrates of $F$. solani B in PDBA (1), no filtrates in PDBA (2), F. oxysporum vanillae in PDBA (3), $F$. solani B in NBA (4), no filtrate in NBA (5), and $F$. oxysporum vanillae in NBA (6).

\section{ACIDITY OF MEDIA USED IN THE EXPERIMENTS}

Tahle 2 illustrates the acidity of the media used. Generally, PDB was acidic (pH 3.6-5.0) and NB neutral to slightly basic (pH 6.6-8.8), with no marked differences between filtrates and controls.

\section{DISCUSSION}

There was little evidence of the selectivity of fusarial fungus filtrates in media. The only media with slight selective inhibitory properties were NBA and PDBA with filtrates of $F$. solani (B). Other fungi were inhibited in experiments of linear growth in agar only. 
Spore germination of this fungus on the surface of washed cellophane did not exhibit the expected enhanced sporulation in its own filtrate. Spores germinated slowest over its own filtrate, whether the media had been

TABLE 1.-Fungus isolations from unsterilized garden soil plates using filtrate media

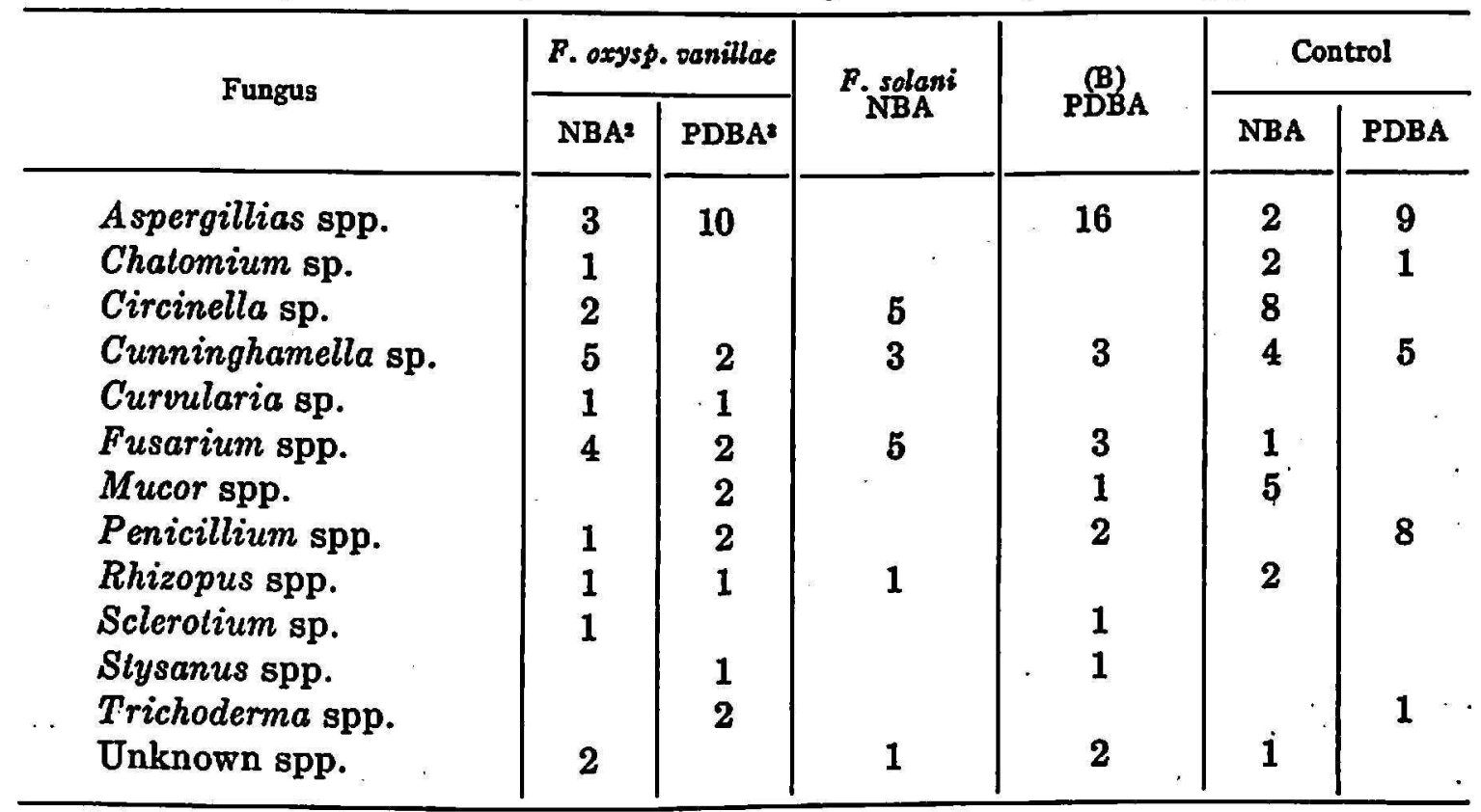

1 Results are averages of 2 trials.

2 Nutrient-broth agar (NBA).

' Potato-Dextrose broth agar (PDBA).

TABLE 2-pH's of filtrate and control media ${ }^{1}$

\begin{tabular}{l|c|c|c|c}
\hline \multirow{2}{*}{ Fungus } & \multicolumn{2}{|c|}{ NB2 } & \multicolumn{2}{c}{ PDBs } \\
\cline { 2 - 6 } & Seitz & Heat & Seitz & Heat \\
\hline F. oxysporum vanillae (D) & 8.72 & 8.70 & 3.95 & 3.60 \\
F. oxysporum (A) & 8.15 & 8.30 & 4.25 & 4.40 \\
F. solani (B) & 8.10 & 8.78 & 3.60 & 3.72 \\
F. solani (C) & 8.12 & 7.85 & 4.20 & 3.65 \\
Control & 6.60 & 6.70 & 5.07 & 4.70 \\
\hline
\end{tabular}

1 Results are averages of 2 trials.

2 NB: Nutrient Broth.

PDB: Potato Dextrose Broth.

sterilized in the autoclave or through a Seitz filter. The control broths allowed a more rapid germination, but after 9 to 12 hours of incubation germination was similar to the controls (94 to 98 percent).

Selective inhibition of filtrates in soil plates was not apparent for any of the filtrate media, and species of Fusarium could not easily be distinguished from each other. There was no evidence that the numbers or types of fungi 
developing in soil plates with filtrate media were different from each other or significantly different from the controls.

The large differences in spore germination rate observed between the controls and filtrates are possibly due to nutrient deficiency, although the presence of an inhibiting factor was not sought. The acidity of the media apparently had no effect. Our observations suggest that filtrates are not sufficiently selective to warrant their use in agar media.

\section{SUMMARY}

Filtrates of Fusarium oxysporum f. sp. vanillae (Tucker) Gordon, Schlecht. and two isolates of $F$. solani (Mart.) Appel \& Wr., grown in nutrient and potato dextrose broth, effected spore germination, linear growth in agar, and colony development in soil plates of these and other fungi. There was not enough sign of selectivity in these filtrates to warrant their use for selective isolation of fungi from soil.

\section{RESUMEN}

Filtrados de Fusarium oxysporium f. sp. vanillae (Tucker) Gordon, Schlecht. y de $F$. solani (Mart.) Appel \& Wr. cultivados en un caldo nutrimental y en agar-papa con dextrosa, produjeron esporas, lograron un crecimiento lineal en agar y el desarrollo de colonias en platillos con suelos que contenían éstos y otros hongos. No hubo suficientes señales de selectividad en estos filtrados que puedan justificar su uso para seleccionar y aislar hongos del suelo.

\section{LITERATURE CITED}

1. Bouhot, D., and Billote, J. M., Recherches sur l'ecologie des champignons parasites dans le sol, II, Choix d'un milieu nutritif pour l'isolament selectif de $F u$ sarium oxysporum et Fusarium solani du sol., Am. Epiphyties 15: 45-56, 1964.

2. Nash, Shirley M., and Snyder, W. C., Quantitative estimations by plate counts of propagules of bean root rot Fusarium in field soils, Phytopathology 52: 567-72, 1962.

3. Papavizas, G. C., Evaluation of various media and antimicrobial agents for isolation of Fusarium from soil, Phytopathology 67: 848-52, 1967.

4. Parmeter, J. R., Jr., and Hood, J. L., The use of Fusarium culture filtrate media in the isolation of fusaria from soil, Phytopathology 51: 164-68, 1961.

5. Parmeter, J. R., Jr., and Hood, J. L., Use of ultraviolet light in isolations of certain fungi from soil, Phytopathology 58: 376-77, 1962.

6. Singh, R. S., and Nene, Y. L., Malachite green in synthetic medium for the isolation of Fusarium spp. from plant tissues, Naturwissenshaften 62: 94, 1965. 